\title{
Functional Performance Among Active Female Soccer Players After Unilateral Primary Anterior Cruciate Ligament Reconstruction Compared With Knee-Healthy Controls
}

\author{
Anne Fältström, Martin Hägglund and Joanna Kvist
}

Journal Article

\section{Tweet}

N.B.: When citing this work, cite the original article.

Original Publication:

Anne Fältström, Martin Hägglund and Joanna Kvist, Functional Performance Among Active Female Soccer Players After Unilateral Primary Anterior Cruciate Ligament Reconstruction Compared With Knee-Healthy Controls, American Journal of Sports Medicine, 2016.

http://dx.doi.org/10.1177/0363546516667266

Copyright: SAGE Publications (UK and US): No SAGE Choice

http://www.uk.sagepub.com/home.nav

Postprint available at: Linköping University Electronic Press

http://urn.kb.se/resolve?urn=urn:nbn:se:liu:diva-131850

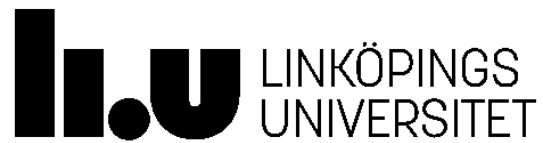


Title: Functional Performance among Active Female Soccer Players after Unilateral Primary Anterior Cruciate Ligament Reconstruction Compared with Knee-healthy Controls

Authors: Anne Fältström, ${ }^{* \dagger}$ RPT, Martin Hägglund*, RPT, Assoc Professor, and Joanna Kvist*, RPT, Professor

${ }^{* \dagger}$ Region Jönköping County, Rehabilitation Centre, Ryhov County Hospital, Jönköping, Sweden.

*Division of Physiotherapy, Department of Medical and Health Sciences, Linköping University, Linköping, Sweden

Corresponding author: Joanna Kvist, Division of Physiotherapy, Department of Medical and Health Sciences, Linköping University, 58183 Linköping, Sweden E-mail: joanna.kvist@liu.se

Telephone: +46 (0) 13284664

\section{ACKNOWLEDGMENTS}

The authors gratefully acknowledge Isabella Manzoni (IM) for analyzing all the films. The authors also acknowledge all soccer players for their participation in this study, and all the physiotherapists who allowed access to their physiotherapist clinics for testing. The study was supported financially by Futurum-the Academy for Healthcare, Region Jönköping County, the Medical Research Council of Southeast Sweden, the Faculty of Health Sciences at Linköping University, Swedish Research Council for Sport Science (CIF), and the Swedish Football Association. 


\section{ABSTRACT}

Background: Good functional performance with limb symmetry is believed to be important to minimize the risk of injury after a return to pivoting and contact sports following anterior cruciate ligament reconstruction (ACLR).

Purpose: To investigate any side-to-side limb differences in functional performance and movement asymmetries in female soccer players with a primary unilateral ACLR knee and to compare these players with knee-healthy controls from the same soccer teams.

Study Design: Cross-sectional study.

Methods: 77 female active soccer players with an ACLR knee, median 18 months after reconstruction (interquartile range [IQR] 14.5, range 7-39 months), and 77 knee-healthy female soccer players were included. Mean ages for ACLR players and controls were $20.1 \pm$ 2.3 and $19.5 \pm 2.2$ years, respectively. A battery of tests was used to assess postural control; the star excursion balance test, and hop performance; the one-leg hop for distance, the five jump test (5JT), and the side hop. Movement asymmetries in the lower limbs and trunk were assessed with the drop vertical jump (DVJ) and the tuck jump using two-dimensional analyses.

Results: The reconstructed and uninvolved limbs did not differ in any of the tests. In the 5JT, ACLR players performed worse than controls (mean $8.75 \pm 1.05 \mathrm{~m}$ vs. $9.09 \pm 0.89 \mathrm{~m}, P=$ .034). On the DVJ, the ACLR limb compared with the control players' matched limb (for leg dominance) had significantly less knee valgus motion in the frontal plane (median $0.028 \mathrm{~m}$, IQR 0.049 vs. $0.045 \mathrm{~m}$, IQR $0.043, P=.004$ ) and a lower probability of high knee abduction moment (pKAM) (median 69.2\%, IQR 44.4 vs. 79.8\%, IQR 44.8, $P=.043$ ). Nine to $49 \%$ of players in both groups performed outside recommended guidelines on the different tests. Only fourteen (18\%) ACLR players and 15 (19\%) controls had results that met the recommended guidelines for all five tests $(P=.837)$. 
Conclusions: The reconstructed and uninvolved limbs did not differ, and ACLR players and controls differed only minimally on the functional performance tests, indicating similar function. It is worth noting that many of the ACLR and control players had movement asymmetries and a high pKAM pattern, which previously have been associated with an increased risk for both primary and secondary ACL injury in female athletes.

What is known about the subject: Anterior cruciate ligament (ACL) injury is a severe and common injury in female soccer players. The risk of sustaining an additional ACL injury to the ipsi- or contralateral knee is increased with a return to cutting and pivoting sports after an ACL reconstruction (ACLR), especially in the young female population. Many patients return to sport (RTS) after ACLR with persistent decreased performance on functional tests, which may predispose them to a new injury. Several of the functional tests used in previous studies have been done in a laboratory setting, which may have disadvantages of being high-tech, expensive, and time consuming, and may thus have less clinical applicability.

What this study adds: The present study showed that the reconstructed and uninvolved limbs of female players who had returned to soccer after ACLR did not differ on functional performance tests performed in a clinical setting. Furthermore, the ACLR players and kneehealthy controls differed only minimally; ACLR players performed worse on the five jump test, had less knee valgus motion in the frontal plane in a drop vertical jump, and a lower probability of knee abduction moment compared with controls. The results at the group level indicated that ACLR players performed in line with recommended guidelines suggested in the literature. Thus, the ACLR players seem to have restored their function, as measured by the tests in the present study. However, on the individual level, many players (9-49\%), both ACLR players and knee-healthy controls, had side-to-side differences and movement 
asymmetries, which previously have been associated with an increased risk for primary and secondary ACL injury in female athletes. 


\section{INTRODUCTION}

Anterior cruciate ligament (ACL) injury is a severe and common injury in soccer players, and females have a 2-3-fold greater risk compared to men. ${ }^{43}$ Return to sports (RTS) is a common goal after an ACL reconstruction (ACLR) ${ }^{23}$ but increases the risk of additional ACL injury to the ipsi- or contralateral knee, especially in the young female population, ${ }^{34}$ as well as of sustaining other knee injuries. ${ }^{32,42}$

RTS should be based on fulfillment of specific criteria and a patient-tailored process. ${ }^{11}$ Suggested RTS criteria incorporate evaluation of the functional performance of limb strength (power and endurance), knee stability, bilateral limb symmetry, postural control, agility, technique with sport-specific tasks, and patient-reported outcomes. ${ }^{11,29}$ These components are considered important in rehabilitation after ACLR for successful results i.e. RTS, no giving way, quadriceps and hamstring strength $>90 \%$ of the uninvolved limb, and high scores (85 to 90\%) on patient-reported outcomes. ${ }^{23}$ They also are considered to be important for reducing risk of subsequent injuries and other complications, ${ }^{11,29}$ but no formal guidelines ${ }^{16}$ or functional tests ${ }^{30}$ to indicate safe RTS currently exist. A battery of tests is recommended for evaluating functional performance, ${ }^{11,29,41}$ which includes both quantitative and qualitative assessment. ${ }^{12}$ Most recommended test batteries evaluate strength and hop performance (quantitative), ${ }^{30,31}$ but not postural control and movement asymmetries, such as foot, knee, hip, and trunk movement (qualitative).

Valgus motion, a combination of hip internal rotation, knee valgus, and tibial internal or external rotation, is a common ACL injury mechanism in females. ${ }^{39}$ Evaluation of side-to-side differences in knee motion and hip and trunk movement has been suggested to identify female athletes, both uninjured ${ }^{19}$ and with an ACLR knee ${ }^{36}$ at high risk for ACL injury. At the time of $\mathrm{RTS}^{28}$ and up to 7 years after ACLR, ${ }^{40}$ side-to-side differences in postural control, ${ }^{9}$ altered movement patterns in the knee and hip, and deficits in force development in the vertical jump 
10, 28, 40 may persist in ACLR athletes compared with knee-healthy controls. Thus, it is important to test these functions, but many of the used tests have been done in a laboratory setting and may have less clinical applicability. ${ }^{9,}$ 10, 19, 28, 36, 40 In the present study we evaluated functional performance in a high risk group of female soccer players with an ACLR knee using a battery of tests commonly used in clinical practice to see if these tests could discriminate between ACLR players and knee-healthy controls, and between the reconstructed and uninvolved limb.

The aim of this study was to investigate any side-to-side limb differences in functional performance and movement asymmetries in female soccer players with a primary unilateral ACLR knee and to compare these players with knee-healthy controls from the same soccer teams. Our hypotheses were that the ACLR players would have side-to-side differences between the limbs and persistent movement asymmetries and poorer function as compared with the controls.

\section{MATERIALS AND METHODS}

The present study includes cross-sectional baseline measurements from an ongoing prospective cohort study.

\section{Participants}

The study population was identified through the Swedish national ACL register, which captures $>90 \%$ of all ACLRs in the country, ${ }^{22}$ and via advertisement on the websites of three regional soccer districts near the university (to facilitate testing). Inclusion criteria were currently active female soccer player (participating fully in soccer training with the team, any playing level), age 16-25 years, having undergone primary ACLR between 6-36 months 
previously at any clinic in the three regional soccer districts. Exclusion criteria were having an associated posterior cruciate ligament injury and/or surgically treated injuries to either the medial or lateral collateral ligament of the knee. Data were collected in the soccer pre-season (January-April) in 2013 and again in 2014.

We identified 453 patients in the ACL register who met inclusion criteria, and 70 were included. An additional seven active ACLR players (who were not registered in the ACL register) responded to the regional advertisements and were also included, for a total of 77 female ACLR players (Figure 1). ACL injury and soccer-related factors for the ACLR players are presented in Table 1.

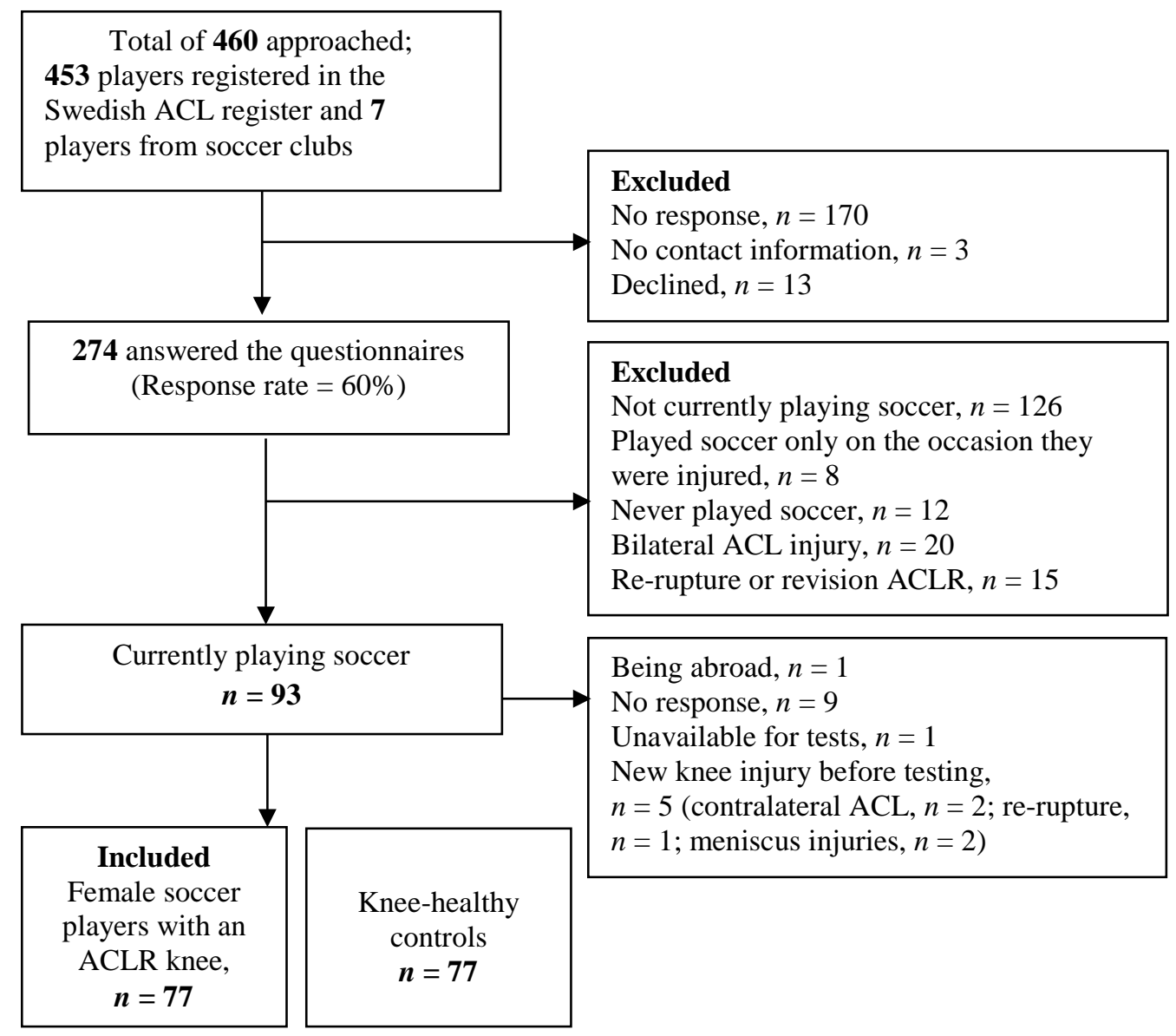

Figure 1. Study flowchart. 


\section{TABLE 1}

Anterior cruciate ligament (ACL) injury and soccer-related factors for female soccer players with an ACL reconstructed (ACLR) knee $^{a}$

\begin{tabular}{|c|c|}
\hline ACL injury and soccer-related factors & $\begin{array}{l}\text { ACLR players } \\
n=77\end{array}$ \\
\hline \multicolumn{2}{|l|}{ Injury mechanism, n (\%) } \\
\hline Contact & $28(36)$ \\
\hline Noncontact & $49(64)$ \\
\hline Age at $A C L R$, mean $\pm S D, y$ & $18.4 \pm 2.3$ \\
\hline Time between injury and ACLR, median, (IQR), mo & $4(5)$ \\
\hline$\leq 3$ months, n $(\%)$ & $23(30)$ \\
\hline$>3-12$ months, $n(\%)$ & $48(62)$ \\
\hline >12 months, n (\%) & $6(8)$ \\
\hline Time from ACLR to follow-up, median, (IQR), mo & $18(14.5)$ \\
\hline 7-12 months, n (\%) & $14(18)$ \\
\hline$>12-24$ months, n (\%) & $41(53)$ \\
\hline$>24$ months, $\mathrm{n}(\%)$ & $22(29)$ \\
\hline \multicolumn{2}{|l|}{ Graft, n (\%) } \\
\hline Hamstrings & $74(96)$ \\
\hline Patellar tendon & $1(1)$ \\
\hline Others & $2(3)$ \\
\hline \multicolumn{2}{|l|}{ ACLR knee, n (\%) } \\
\hline Right & $41(53)$ \\
\hline Left & $36(47)$ \\
\hline ACLR in the dominant limb (preferred kicking leg), $n$ (\%) & $44(57)$ \\
\hline \multicolumn{2}{|l|}{ Presence of concomitant injuries at ACLR, n (\%) } \\
\hline Meniscus injury (medial/lateral) & $31(40)$ \\
\hline Articular cartilage injury & $5(6)$ \\
\hline Time from ACLR to full training with the team, median, (IQR), mo & $9(5)$ \\
\hline Time from ACLR to first match, median, (IQR), mo ${ }^{b}$ & $11(5)$ \\
\hline $\begin{array}{l}\text { Time from return to full training with the team to follow-up, } \\
\text { median, (IQR), mo }\end{array}$ & $7(13)$ \\
\hline$\leq 3$ months, $\mathrm{n}(\%)$ & $23(30)$ \\
\hline$>3-12$ months, $n(\%)$ & $25(32)$ \\
\hline$>12$ months, $\mathrm{n}(\%)$ & $29(38)$ \\
\hline Time from return to match play to follow-up, median, (IQR), mo ${ }^{b}$ & $9(12)$ \\
\hline$\leq 3$ months, $\mathrm{n}(\%)$ & $19(29)$ \\
\hline$>3-12$ months, $n(\%)$ & $26(40)$ \\
\hline >12 months, n (\%) & $20(31)$ \\
\hline \multicolumn{2}{|l|}{ Level of play as compared to before the ACL injury, n (\%) } \\
\hline Same level & $48(62)$ \\
\hline Higher level & $13(17)$ \\
\hline Lower level & $16(21)$ \\
\hline IKDC (0-100), mean \pm SD & $83.9 \pm 11.8$ \\
\hline
\end{tabular}

${ }^{a} \mathrm{ACLR}$, anterior cruciate ligament reconstruction; IKDC, International Knee Documentation Committee Subjective Knee Evaluation Form; IQR, interquartile range; SD, standard deviation.

${ }^{b} \mathrm{n}=65,12$ players had not played any matches after ACLR at the time of follow-up. 
ACLR players were compared with 77 control players (without ACL injury or ACLR and with no other current injuries that kept them away from play), recruited via the trainer from the same team to ensure that groups were as similar as possible for soccer exposure, age, and playing position. The trainer was contacted by phone and asked to choose a teammate (control) as close to these criteria as possible. Ten of the ACLR players and 9 of the controls (12.5\%) played at the elite level (two top divisions in Sweden). In both groups, 58 (75\%) played in the third to sixth divisions, and the remaining 9 and 10 players (12.5\%), respectively in the lowest division or youth play. The players represented 61 different teams. At study start, six pilot tests were done to check the testing procedure (not included).

All players received written and oral information about the study, which was approved by the Regional Ethical Review Board (Dnr 2012/24-31 and 2013/75-32) and Swedish national ACL Register board. After giving informed consent, players received a questionnaire about demographic and soccer-related factors to complete at home before the testing session. Each player's preferred kicking leg was used as the dominant limb; for players who cited "both” as preferred, the right limb was analyzed as dominant. The ACLR players also filled out the International Knee Documentation Committee Subjective Knee Evaluation Form, ${ }^{20}$ with 10 items measuring knee symptoms, function, and activity limitations in daily living and sports. Scores range from 0 (worst) to 100 (best), and the test is valid, responsive for change, and test-retest reliable. ${ }^{14,20}$

\section{Anthropometrics}

All measurements and tests were supervised by the same experienced test leader (AF), who gave standardized verbal instructions. Tests were performed at 13 physiotherapy clinics near where the players lived. Data were collected in a single testing session, beginning with height and weight, followed by a general joint laxity assessment using the Beighton method, ${ }^{4}$ which 
grades from $0-9$, with $>4$ indicating generalized joint laxity. The intra- and inter-reliability of the $0-9$ scale and category scores are good to very good (Spearman $\rho=.81-.86$ and $.75-.87$, respectively). ${ }^{6}$ A general clinical knee examination was performed in the control group to exclude obvious injury of the ligaments or the meniscus. Knee range of motion (ROM), extension, and flexion were measured in the supine position using a goniometer. Knee stability was evaluated manually with the Lachman and pivot shift tests. A KT-1000 arthrometer (MEDmetric, Corp., San Diego, CA) was used to assess the amount of anterior translation of the tibia relative to the femur. The max manual test, where one hand pulls the tibia forward, was used, with a side-to-side difference of $\geq 3 \mathrm{~mm}$ defined as abnormal. ${ }^{3,8}$ The inter-rater reliability of KT-1000 is good (ICC, 0.79) with experienced raters. ${ }^{5}$ To adjust some test scores, leg length (anterior superior iliac spine to center of medial malleolus) and tibia length (lateral knee joint line to center of lateral malleolus) were measured with a measuring tape with the player in the supine position.

\section{Functional performance tests}

The players performed a postural control test and five hop tests as measures of functional performance (Figure 2). Hop tests reflect various qualities (movement asymmetries, maximum and endurance hop performance) with different demands and are feasible for use in a clinical setting. The supplementary Appendix has a detailed description of the tests. (available online at http://ajsm.sagepub.com/supplemental). 

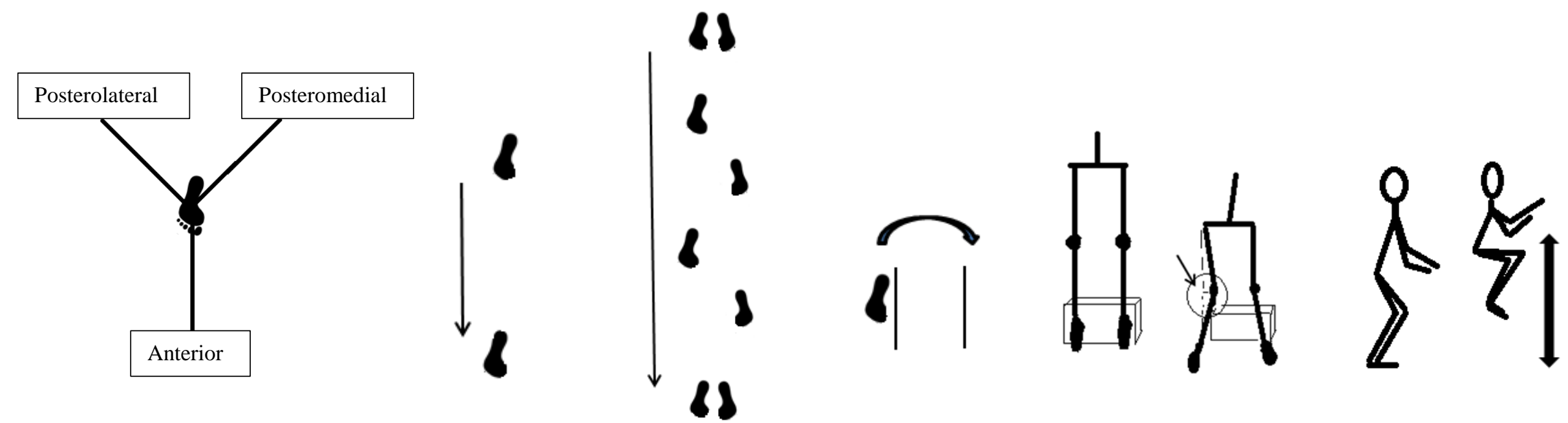

Star excursion balance test

One-leg hop for distance

Five jump test

Side hop

Drop vertical jump

Tuck jump

Figure 2. The functional performance tests measuring postural control (star excursion balance test), maximum hop (one-leg hop for distance and five jump test), endurance hop (side hop), and movement asymmetries (drop vertical jump and tuck jump). 
All players were tested by the same tester (AF), not blinded to whether the subject was an ACLR player or control, according to a test protocol in the same order: 1) the star excursion balance test $\left.(\mathrm{SEBT})^{38} ; 2\right)$ the one-leg hop test for distance $\left.{ }^{15} ; 3\right)$ the five jump test $\left.(5 \mathrm{JT})^{7} ; 4\right)$ the drop vertical jump (DVJ) ${ }^{25-27}$; 5) the tuck jump ${ }^{24}$; and 6) the side hop. ${ }^{15}$ Indoor sport shoes were used in all tests except the SEBT, where players were barefoot. In the SEBT, players had three practice trials and then performed three attempts in each direction. The best result of the three attempts was used and the score was normalized to the leg length (test value/leg length $\times$ 100). A composite score was calculated for each limb as the average of the three normalized measurements in the different directions. After the SEBT, a standardized warm-up program was performed for 5-10 minutes with different running exercises typical for soccer, followed by 10 squats, 10 toe rises, and rope skipping for 1 minute. The ACLR players started the testing on their uninvolved limb, and controls started with their right limb. ${ }^{31}$ Players were allowed a few practice trials before each of the five jump tests. They performed three maximum trials of the one-leg hop for distance, 5JT, and DVJ. The best result of the attempts was recorded in $\mathrm{m}$ in the one-leg hop for distance and the 5JT. However, if hop lengths increased in all three hops in the one-leg hop for distance, additional hops were performed until no further increase occurred. About 3 minutes of rest were interposed between the different tests. ${ }^{15}$

A limb symmetry index (LSI) was calculated as “ACLR limb/uninvolved limb $\times 100$ ” or “nondominant limb/dominant limb $\times 100$ ” for the controls and used as one variable for the SEBT, one-leg hop test for distance, and side hop. Knee motion (medial/valgus or lateral/varus knee displacement) was calculated in $\mathrm{m}$ as the frontal plane displacement of the knee from initial contact (when the feet just touched the ground) to the end of the deceleration phase (deepest knee flexion position) of the DVJ. The knee flexion ROM (degrees) was also 
measured from initial contact to the end of the deceleration phase of the DVJ. Knee motion and flexion angle, measured with motion analysis software Dartfish ProSuite (Dartfish Ltd, Fribourg, Switzerland), were used to calculate knee abduction moment (KAM) according to a nomogram to predict the probability of high knee abduction moment (pKAM). ${ }^{25}$ These calculations were assessed from the films by the same person (IM), who was blinded to group belonging. The range of pKAM is $0-1$, which is comparable to 0 (lowest) $-100 \%$ (highest). The nomogram is based on the player's weight, tibia length, knee motion in the frontal plane, and knee flexion ROM, and a surrogate value for hamstring-quadriceps ratio (multiplying the player's mass by 0.01 and adding the resultant value to 1.10$).{ }^{25-27}$

\section{Recommended guidelines for successful outcome}

Values indicating scores outside recommended guidelines in the present study were as follows: SEBT, a difference between limbs in the anterior reach distance $\geq 0.04 \mathrm{~m}$ and composite score reach distance $\leq 94 \%$ of limb length ${ }^{38}$; hop tests, an LSI of $<90 \%$ and $>110 \%{ }^{15}$; and tuck jump, six or more flawed techniques. ${ }^{24}$ No recommended guidelines regarding cut-offs for DVJ were available and therefore the tertile of the highest values based on the total sample in the present study (all 154 players) in knee motion and side difference in frontal plane, and pKAM measured with DVJ were analyzed and used as a cut-off value.

\section{Statistical methods}

An a priori sample-size calculation showed that 73 players in each group had to be included to detect at least a $10 \%$ difference in the one-leg hop for distance (SD $28^{15}$ ) at an alpha level of 0.05 and to reach $80 \%$ power. All statistical analyses were performed using IBM SPSS Statistics for Windows (version 22.0; IBM Corp; Armonk, NY). Mean \pm standard deviation or median and range/interquartile range (IQR) were calculated for descriptive statistics. Paired- 
sample $t$-tests and the Wilcoxon signed ranks test for normal and non-normally distributed variables, respectively, were used to compare differences between limbs within ACLR players and within controls. Between-group comparisons (demographics, anthropometric factors, functional performance tests, number of players with side-to-side differences) were made using the student's $t$, Mann-Whitney $U$, Chi-square, and Fisher's exact tests as appropriate. To study the possible influence of time from reconstruction to follow-up, a subgroup analysis was performed comparing the reconstructed versus the uninvolved limb for ACLR players who had their reconstruction $\leq 18$ months $(\mathrm{n}=39)$ or $>18$ months $(\mathrm{n}=38)$ prior to follow-up using the paired-sample t-tests and the Wilcoxon signed ranks test. The significance level was set at $P<.05$.

\section{RESULTS}

Demographics did not differ between ACLR players and controls (Table 2). Compared with controls, ACLR players had greater side-to-side differences in anterior translation of the tibia in relation to the femur, measured with KT-1000 $(P<.001)$, and a higher proportion of Lachman graded as a soft endpoint $(P<.001)$ and rotational stability graded as a positive pivot shift $(P=.029)$. The median side-to-side difference in the KT-1000 manual max test was $2 \mathrm{~mm}$ (IQR 3, range -3 to $9 \mathrm{~mm}$ ) in ACLR players and $0 \mathrm{~mm}$ (IQR 1, range -1 to $3 \mathrm{~mm}$ ) in the controls. ACLR players had more side-to-side differences both in extension and flexion ROM compared with controls $(P<.001)$. Beighton scores did not differ between groups $(P=$ $.955)$. 
TABLE 2

Demographic, anthropometric, and soccer-related factors of female soccer players with an anterior cruciate ligament reconstructed (ACLR) knee and knee-healthy controls ${ }^{a}$

\begin{tabular}{|c|c|c|c|}
\hline Demographic, anthropometric, and soccer-related factors & $\begin{array}{c}\text { ACLR players } \\
\boldsymbol{n}=\mathbf{7 7}\end{array}$ & $\begin{array}{c}\text { Controls } \\
n=77 \\
\end{array}$ & $P$ value \\
\hline Age, $y$ & $20.1 \pm 2.3$ & $19.5 \pm 2.2$ & .114 \\
\hline Height, m & $1.68 \pm 0.05$ & $1.68 \pm 0.06$ & .827 \\
\hline BMI, $\mathbf{k g} / \mathbf{m}^{2}$ & $22.8 \pm 2.7$ & $22.1 \pm 2.0$ & .067 \\
\hline Beighton score (0-9), median (IQR) & $2(4)$ & $2(3)$ & .955 \\
\hline Beighton $>4, \mathrm{n}(\%)$ & $18(23)$ & $15(19)$ & .556 \\
\hline KT-1000 manual max, side-to-side difference, $\geq 3 \mathrm{~mm}, \mathrm{n}(\%)$ & 30 (39) & $3(4)$ & $<.001$ \\
\hline 3-5 mm, n (\%) & $25(32)$ & $3(4)$ & \\
\hline$>5$ mm, n (\%) & $5(6)$ & $0(0)$ & \\
\hline Lachman graded as soft endpoint, $n$ (\%) & $17(22)$ & $0(0)$ & $<.001$ \\
\hline Positive pivot shift, n (\%) & $5(6)$ & $0(0)$ & .029 \\
\hline ROM flexion, side-to-side difference $\geq 10^{\circ}$ & $16(21)$ & $0(0)$ & $<001$ \\
\hline ROM extension, side-to-side difference $\geq 5^{\circ}$ & $23(30)$ & $9(12)$ & $<.001$ \\
\hline \multicolumn{4}{|l|}{ Playing position, n (\%) } \\
\hline Goalkeeper & $2(3)$ & $2(3)$ & .965 \\
\hline Defender & $26(34)$ & $28(36)$ & \\
\hline Midfield & 38 (49) & 38 (49) & \\
\hline Forward & $11(14)$ & $9(12)$ & \\
\hline \multicolumn{4}{|l|}{ Dominant limb (preferred kicking leg), n (\%) } \\
\hline Right & $61(79)$ & $69(90)$ & .146 \\
\hline Left & $5(6)$ & $1(1)$ & \\
\hline Both & $11(14)$ & $7(9)$ & \\
\hline
\end{tabular}

${ }^{a}$ Values: mean \pm standard deviation unless otherwise stated. BMI, body mass index; ROM, range of motion; IQR, interquartile range.

\section{Functional performance tests}

\section{Within-group comparisons between limbs}

The ACLR players' reconstructed and uninvolved limbs did not differ in any tests. The subgroup analysis of ACLR players who had their reconstruction $\leq 18$ or $>18$ months prior to follow-up showed similar results with no between-limb differences in any of the tests (all $P \geq$ .05). The controls had very small (less than $0.01 \mathrm{~m}$ ) but statistically significant differences between dominant and nondominant limbs on the SEBT anterior $(P=.042)$, posteromedial $(P$ $=.029)$, and composite score $(P=.013)$, with better performance of the nondominant limb. 
Between-group comparisons

The only between-group differences were seen for the 5JT and DVJ (knee motion in frontal plane and pKAM) (Table 3). ACLR players performed worse than controls on the 5JT ( $P=$ .034). For the DVJ, the ACLR limb compared with the matched limb regarding dominance in the controls, showed significantly less valgus (medial) motion (median $0.028 \mathrm{~m}$, IQR 0.049 vs. $0.045 \mathrm{~m}$, IQR 0.043, $P=.004$ ) and a lower pKAM (median 69.2\%, IQR 44.4 vs. 79.8\%, IQR 44.8, $P=.043$ ).

The proportion of players with results classified outside recommended guidelines was 9-49\% for ACLR players and 10-44\% for controls and did not differ between groups (all $P>$ .05, Figure 3). Only fourteen (18\%) ACLR players and 15 (19\%) controls had results that met the recommended guidelines for all five tests $(P=.837)$. The highest tertile ( $n=51$ of 154 players) results in DVJ were; knee motion and side difference in frontal plane $\geq 0.065 \mathrm{~m}$ and $\geq 0.041 \mathrm{~m}$, respectively, and $\mathrm{pKAM} \geq 91 \%$. The proportion of ACLR players versus controls who were in the highest tertile for DVJ did not differ significantly for any of the tests (all $P>$ .05 , Figure 4). 
TABLE 3

Absolute scores and limb symmetry index (LSI) for the functional performance tests for the anterior cruciate ligament reconstructed (ACLR) limb and uninvolved limb of female ACLR soccer players and for the nondominant and dominant limbs in the knee-healthy controls ${ }^{a}$

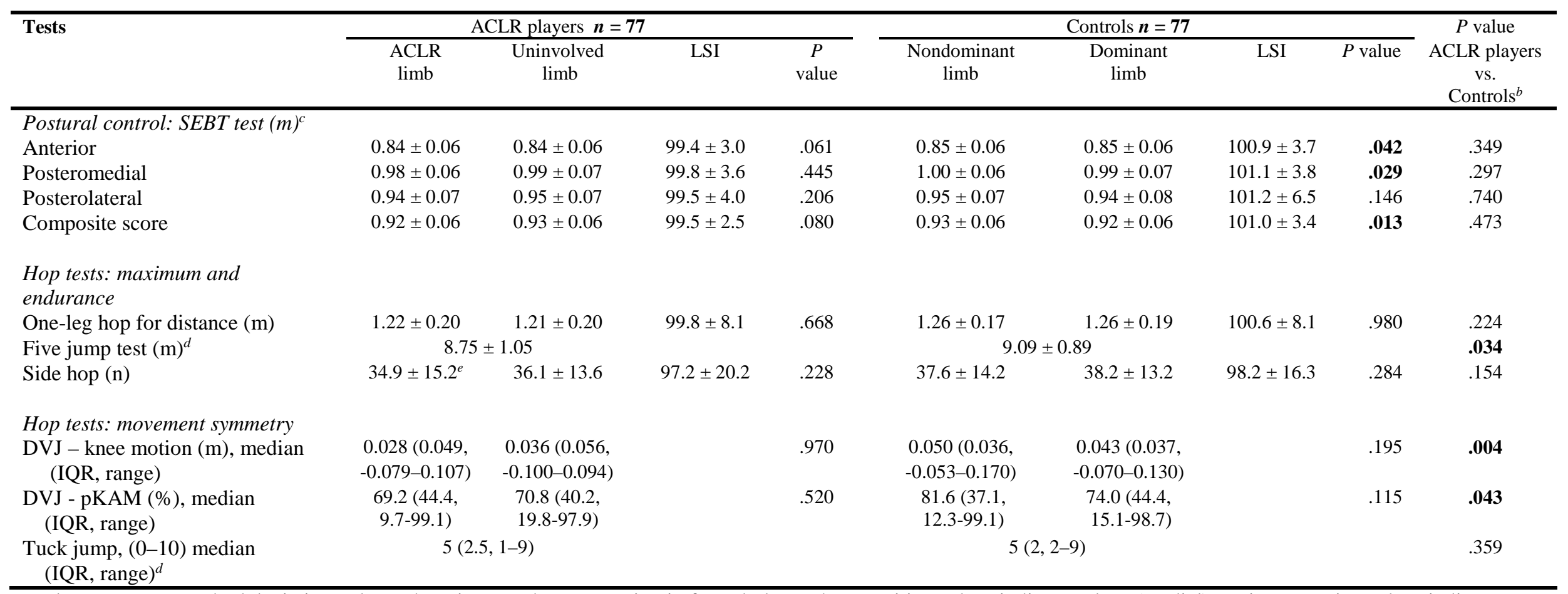

${ }^{a}$ Values: mean \pm standard deviation unless otherwise stated. Knee motion in frontal plane where positive values indicate valgus (medial) motion; negative values indicate varus (lateral) motion. Limb symmetry index, ACLR limb/uninvolved limb and nondominant/dominant limb in percent; DVJ, drop vertical jump; IQR, interquartile range; pKAM, probability of a high knee abduction moment; SEBT, star excursion balance test.

${ }^{b}$ ACLR limb compared with matched control limb from each control participant regarding the dominance of the injured ACLR limb.

${ }^{c}$ Reach distance in $\mathrm{m}$ normalized to the leg length (test value/leg length $\times 100$ ). The composite score is the average of the three normalized measurements in the different directions.

${ }^{d}$ Data apply to both legs.

${ }^{e}$ One person had pain in the ACLR knee on the test day and did not perform the side hop on the ACLR limb; a 0 value was assigned. 


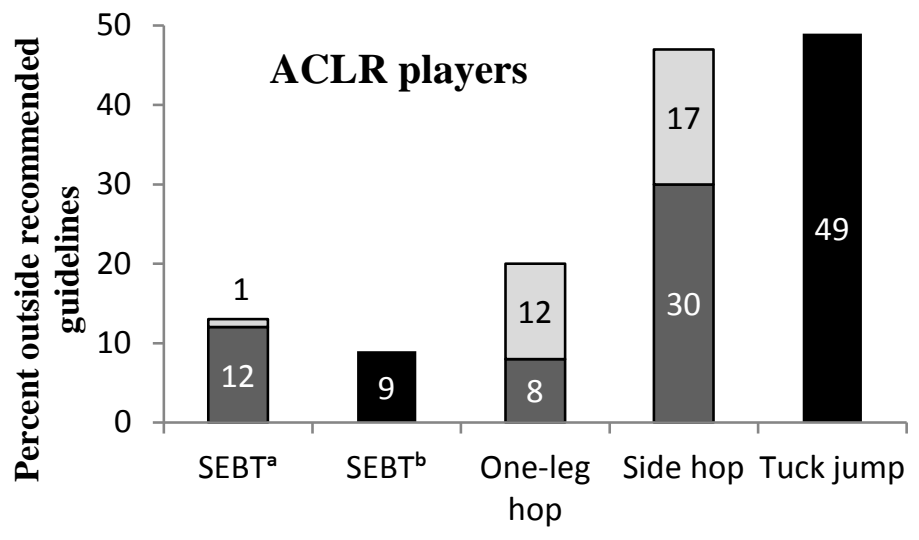

$\square$ ACLR limb $\square$ Uninvolved limb
Data apply to both legs

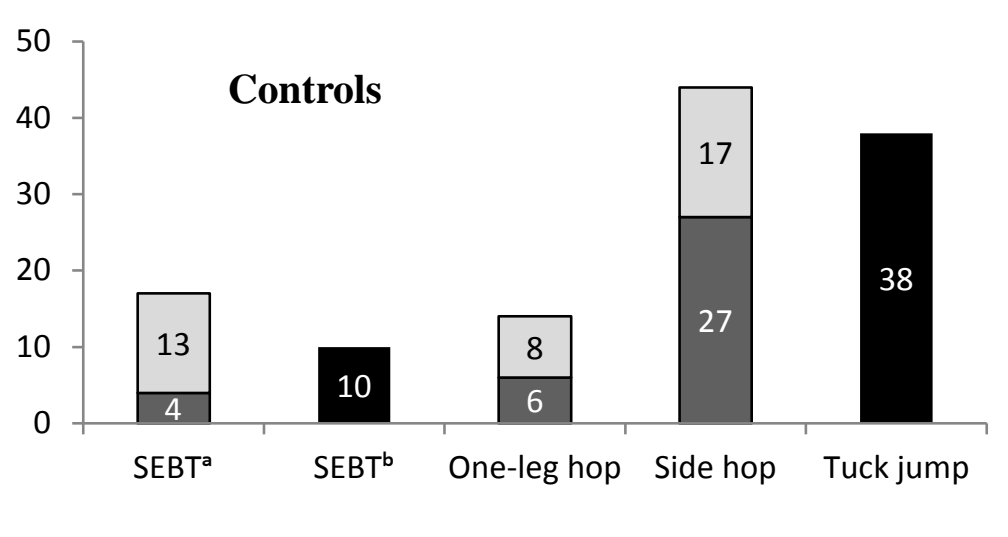

$\square$ Nondominant limb $\square$ Dominant limb $\quad$ Data apply to both legs

Figure 3. Limb differences outside recommended guidelines for various tests for anterior cruciate ligament reconstructed (ACLR) players and knee-healthy controls. Values indicating scores outside recommended guidelines were: Star excursion balance test (SEBT), a difference between limbs in the anterior reach distance $\geq 0.04$ m (SEBT ${ }^{\mathrm{a}}$, ACLR limb=worse compared with uninvolved limb) and composite score reach distance $\leq 94 \%$ of limb length $\left(\mathrm{SEBT}^{\mathrm{b}}\right.$ ); a limb symmetry index of <90\% (ACLR limb) and >110\% (uninvolved limb) in one-leg hop for distance and side hop; six or more flawed techniques (Tuck jump). The proportion of ACLR players vs. controls who were outside recommended guidelines did not differ significantly for any of the test (all $P>.05$ ).

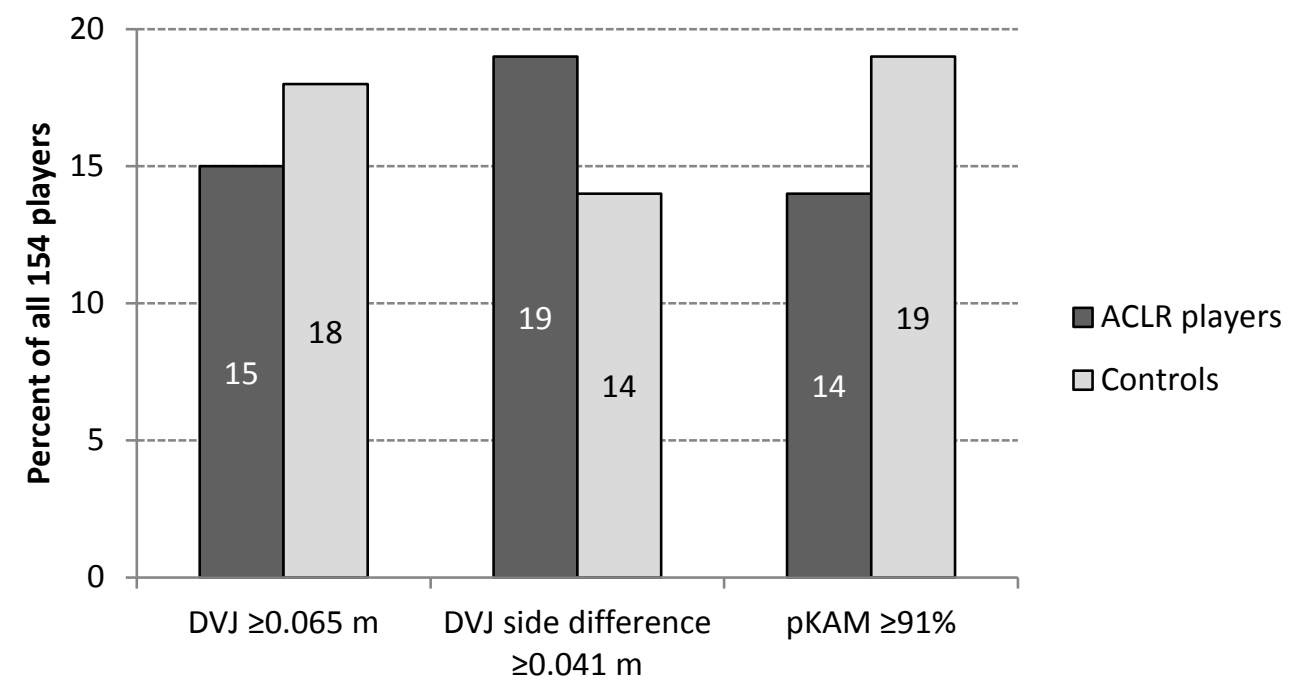

Figure 4. Percent of the anterior cruciate ligament reconstructed (ACLR) players ( $n=77)$ and knee-healthy controls $(n=77)$ in the highest tertile $(n=51 / 154)$ of the results in drop vertical jump (DVJ); knee motion and side difference in frontal plane $\geq 0.065 \mathrm{~m}$ and $\geq 0.041 \mathrm{~m}$, respectively, and in probability of a high knee abduction moment $($ pKAM) $\geq 91 \%$. 


\section{DISCUSSION}

The main findings of this study were that there were no deficiencies in the reconstructed limb compared with the uninvolved limb on any of the functional performance tests. Furthermore, ACLR players and controls differed only slightly on two of the tests, i.e. the 5JT (controls performed better) and DVJ (controls had more valgus motion and higher pKAM). Results at the group level indicated that the ACLR players performed in line with recommended guidelines. ${ }^{15,24,38}$ Thus, the ACLR players seem to have restored their functional performance, as measured by the tests in the present study. However, at the individual level, many ACLR players and knee-healthy controls had side-to-side differences and movement asymmetries, which previously have been associated with an increased risk for primary $^{19}$ and secondary ACL injury ${ }^{34}$ in female athletes. An unexpected result was that the knee-healthy controls had side-to-side differences and movement asymmetries to the same degree as the ACLR players. This needs to be taken under consideration because young female soccer players are a high risk group of sustaining an ACL injury.

In contrast with previous findings, ${ }^{13,21}$ the controls in this study had greater knee valgus movement in the frontal plane measured with DVJ compared with ACLR players (a median difference of $0.017 \mathrm{~m}$ ). High valgus motion has been associated with an increased risk of sustaining a first-time ACL injury, ${ }^{19}$ while in a recent study, ${ }^{21}$ high valgus motion was only predictive for an ACL injury in previous ACLR elite handball and soccer players, and not for previously uninjured players. Today, during postoperative rehabilitation, physiotherapists regularly stress the importance of landing with toes and knees pointed forward, and to minimize knee valgus motion, during landing and takeoff. ACLR players may thus have practiced landing techniques specifically and could also have been aware of the purpose of the test and therefore actively tried to avoid knee valgus motion. The tuck jump test is considered more demanding than the DVJ test because of its plyometric nature, ${ }^{18}$ and the groups did not 
differ for this test. However, almost half of the players had movement asymmetries on the tuck jump that scored outside recommended guidelines. This test is easier for a clinical setting but must be assessed regarding its sensitivity in highlighting players at increased risk for ACL injuries. ${ }^{18}$ Different tests and measurement approaches might also explain the conflicting results. Previous cited studies have often used sophisticated laboratory equipment such as the Biodex balance system, ${ }^{36}$ force plates, ${ }^{10,28,40}$ and three-dimensional (3D) motion analysis. ${ }^{10 \text {, }}$ ${ }^{13,21}$ Hence, the tests used in the present study may not have been sensitive enough to detect existing between-group differences. Myer et $\mathrm{al}^{27}$ reported good correlation between 3D analysis and two-dimensional (2D) analysis in frontal knee motion measurements, but 2D analyses in different settings still could have more sources of errors. Variations in camera placement in the frontal plane and landing technique (e.g., landing with hip rotation or a small distance between feet) could result in measurement errors in knee motion, although we tried to minimize such errors by standardization of camera placements and data collection.

Knee motion in DVJ has been analyzed in many ways. ${ }^{13,19,25-27,33,36}$ In the present study, a clinic-based ACL injury prediction algorithm was used, reporting knee motion in the frontal plane and pKAM. The knee valgus motion in the frontal plane was a median 0.028$0.05 \mathrm{~m}$, but with a wide range from $0.10 \mathrm{~m}$ in varus motion to $0.17 \mathrm{~m}$ in valgus motion. This is in line with previous studies reporting mean values of 0.021-0.041 $\mathrm{m}$ in frontal knee motion using 3D analysis. ${ }^{21,27}$ Landing with varus motion has, to our knowledge, not been discussed as a risk for sustaining an ACL injury.

Between-limb comparisons consistently showed no differences, with only a minimal difference for SEBT for the controls. This small (less than $0.01 \mathrm{~m}$ ) difference is most likely not of clinical importance and within the measurement error. Of the tests measuring postural control and hop performance, ACLR players and controls differed only on the 5JT, which was the only test with worse results for ACLR players. The minimal clinically meaningful 
difference of the $5 \mathrm{JT}$ is unknown, and the mean difference of $\sim 35 \mathrm{~cm}(4 \%)$ between groups is within recommended guidelines and may not be important. Side-to-side differences were mainly found in the most demanding tests, the side hop and tuck jump. Many subjects with an ACLR knee achieve a LSI $>90 \%$ in hop tests within 1 year postoperatively, but more demanding tests like the side hop may take up to 2 years to achieve a LSI $>90 \%{ }^{1}$ Similar to our results, Engelen-van Melick et $\mathrm{al}^{13}$ reported no differences in the one-leg hop for distance and side hop between ACLR subjects 2-7 years postoperatively and healthy controls. However, test batteries discriminate better between involved and uninvolved limbs than do single tests. ${ }^{15,41}$ In line with our results, many patients with an ACL injury or ACLR have LSI values outside recommended guidelines when using test batteries. ${ }^{2,15,41}$ Thus, different demanding tests measuring different qualities should be used in the assessment of the ACLR players before RTS.

A LSI $>90 \%$ is considered essential for successful RTS, i.e., without decreased functional performance, risk for new injury, or developing knee osteoarthritis. ${ }^{41}$ Noteworthy is that Pinczewski et $\mathrm{al}^{37}$ reported that LSI $<90 \%$ on the one-leg hop test at 1 -year follow-up after ACLR predicted radiographic osteoarthritis at 10 years. Side-to-side asymmetries may increase injury risk to both limbs ${ }^{36}$; therefore, we defined LSI $<90 \%$ and $>110 \%$ as being outside recommended guidelines instead of only $<90 \%$ of the uninvolved leg. The recommendation is LSI 100\% in strength and at least 90\% in maximum and endurable hop tests prior to return to contact sports, ${ }^{41}$ but the upper limit is rarely discussed. Having a LSI above $110 \%$ may not be optimal either since the risk of sustaining a contralateral ACL rupture could be even greater compared with a re-rupture. ${ }^{35,36}$ However, evidence is conflicting regarding the validity of hop tests as to whether they can predict knee injuries. ${ }^{17}$

A strength of the present study is the homogeneous cohort of female soccer players with controls recruited from the same soccer teams as the ACLR players, in contrast with most 
studies that include a general population, combining different sports, ages, and sexes. ${ }^{30}$ The time point of RTS can vary greatly and therefore we included players with the range of 6-36 months after ACLR. Functional performance increases with time after ACLR, ${ }^{1}$ and we therefore performed a subgroup analysis of ACLR players being $\leq 18$ months or $>18$ months after their ACLR and this gave similar results as the main analysis with no differences between the reconstructed and uninvolved limbs. Only players who had returned to soccer and were currently playing were studied, so the study may not be extrapolated to soccer players who do not return successfully. As noted, 2D analyses have some limitations but also many advantages, including being low-tech, low cost, and low time-intensive and applicable in a large setting. The tests were performed in different places on different surfaces and conditions, which could have influenced performance and absolute scores; however, the study purpose was to compare between limbs and ACLR players with controls, all tested in the same conditions. Finally, the convener and test leader (AF) was not blinded to group identity, but to minimize measurement errors, the tests were done by the same experienced test leader (AF), and all video analyses were performed by the same person who was blinded to group with a master's degree in movement science (IM).

\section{CONCLUSIONS}

The ACLR and uninvolved limbs did not differ on any of the functional performance tests in this study, and ACLR players and controls differed only minimally. The results at the group level indicate that ACLR players performed in line with recommended guidelines suggested in the literature. Thus, the ACLR players seem to have restored function, as measured by the tests in the present study. However, many ACLR players and controls at the individual level 
had side-to-side differences and movement asymmetries, which have previously been associated with an increased risk for primary and secondary ACL injury in female athletes.

\section{REFERENCES}

1. Abrams GD, Harris JD, Gupta AK, et al. Functional Performance Testing After Anterior Cruciate Ligament Reconstruction: A Systematic Review. Orthop J Sports Med. 2014;2(1):2325967113518305. PMID: 26535266.

2. Ageberg E, Thomee R, Neeter C, Silbernagel KG, Roos EM. Muscle strength and functional performance in patients with anterior cruciate ligament injury treated with training and surgical reconstruction or training only: a two to five-year followup. Arthritis Rheum. 2008;59(12):1773-1779. PMID:19035430.

3. Bach BR, Jr., Warren RF, Flynn WM, Kroll M, Wickiewiecz TL. Arthrometric evaluation of knees that have a torn anterior cruciate ligament. J Bone Joint Surg Am. 1990;72(9):1299-1306. PMID:2229104.

4. Beighton P, Solomon L, Soskolne CL. Articular mobility in an African population. Ann Rheum Dis. 1973;32(5):413-418. PMID:4751776.

5. Berry J, Kramer K, Binkley J, et al. Error estimates in novice and expert raters for the KT-1000 arthrometer. J Orthop Sports Phys Ther. 1999;29(1):49-55. PMID:10100121.

6. Boyle KL, Witt P, Riegger-Krugh C. Intrarater and Interrater Reliability of the Beighton and Horan Joint Mobility Index. J Athl Train. 2003;38(4):281-285. PMID:14737208.

7. Chamari K, Chaouachi A, Hambli M, Kaouech F, Wisloff U, Castagna C. The fivejump test for distance as a field test to assess lower limb explosive power in soccer players. J Strength Cond Res. 2008;22(3):944-950. PMID:18438217.

8. Daniel DM, Stone ML, Sachs R, Malcom L. Instrumented measurement of anterior knee laxity in patients with acute anterior cruciate ligament disruption. Am J Sports Med. 1985;13(6):401-407. PMID:4073348.

9. Delahunt E, Chawke M, Kelleher J, et al. Lower limb kinematics and dynamic postural stability in anterior cruciate ligament-reconstructed female athletes. $J$ Athl Train. 2013;48(2):172-185. PMID:23672381.

10. Delahunt E, Sweeney L, Chawke M, et al. Lower limb kinematic alterations during drop vertical jumps in female athletes who have undergone anterior cruciate ligament reconstruction. J Orthop Res. 2012;30(1):72-78. PMID:21809380. 
11. Ellman MB, Sherman SL, Forsythe B, LaPrade RF, Cole BJ, Bach BR, Jr. Return to Play Following Anterior Cruciate Ligament Reconstruction. J Am Acad Orthop Surg. 2015;23(5):283-296. PMID:25911661.

12. Engelen-van Melick N, van Cingel RE, Tijssen MP, Nijhuis-van der Sanden MW. Assessment of functional performance after anterior cruciate ligament reconstruction: a systematic review of measurement procedures. Knee Surg Sports Traumatol Arthrosc. 2013;21(4):869-879. PMID: 22581194.

13. Engelen-van Melick N, van Cingel RE, van Tienen TG, Nijhuis-van der Sanden MW. Functional performance 2-9 years after ACL reconstruction: cross-sectional comparison between athletes with bone-patellar tendon-bone, semitendinosus/gracilis and healthy controls. Knee Surg Sports Traumatol Arthrosc. 2015. PMID: 26404563.

14. Grevnerts HT, Terwee CB, Kvist J. The measurement properties of the IKDCsubjective knee form. Knee Surg Sports Traumatol Arthrosc. 2015;23(12):3698-3706. PMID: 25193574

15. Gustavsson A, Neeter C, Thomee P, et al. A test battery for evaluating hop performance in patients with an ACL injury and patients who have undergone ACL reconstruction. Knee Surg Sports Traumatol Arthrosc. 2006;14(8):778-788. PMID:16525796.

16. Harris JD, Abrams GD, Bach BR, et al. Return to sport after ACL reconstruction. Orthopedics. 2014;37(2):e103-108. PMID:24679194.

17. Hegedus EJ, McDonough S, Bleakley C, Cook CE, Baxter GD. Clinician-friendly lower extremity physical performance measures in athletes: a systematic review of measurement properties and correlation with injury, part 1 . The tests for knee function including the hop tests. Br J Sports Med. 2015;49(10):642-648. PMID: 25497489.

18. Herrington L, Myer GD, Munro A. Intra and inter-tester reliability of the tuck jump assessment. Phys Ther Sport. 2013;14(3):152-155. PMID:23084318.

19. Hewett TE, Myer GD, Ford KR, et al. Biomechanical measures of neuromuscular control and valgus loading of the knee predict anterior cruciate ligament injury risk in female athletes: a prospective study. Am J Sports Med. 2005;33(4):492-501.

PMID:15722287.

20. Irrgang JJ, Anderson AF, Boland AL, et al. Development and validation of the international knee documentation committee subjective knee form. Am J Sports Med. 2001;29(5):600-613. PMID: 11573919.

21. Krosshaug T, Steffen K, Kristianslund E, et al. The Vertical Drop Jump Is a Poor Screening Test for ACL Injuries in Female Elite Soccer and Handball Players: A Prospective Cohort Study of 710 Athletes. Am J Sports Med. 2016. PMID: 26867936.

22. Kvist J, Kartus J, Karlsson J, Forssblad M. Results from the Swedish national anterior cruciate ligament register. Arthroscopy. 2014;30(7):803-810. PMID:24746404. 
23. Lynch AD, Logerstedt DS, Grindem $\mathrm{H}$, et al. Consensus criteria for defining 'successful outcome' after ACL injury and reconstruction: a Delaware-Oslo ACL cohort investigation. Br J Sports Med. 2015;49(5):335-342. PMID:23881894.

24. Myer GD, Ford KR, Hewett TE. Tuck Jump Assessment for Reducing Anterior Cruciate Ligament Injury Risk. Athl Ther Today. 2008;13(5):39-44. PMID:19936042.

25. Myer GD, Ford KR, Hewett TE. New method to identify athletes at high risk of ACL injury using clinic-based measurements and freeware computer analysis. Br J Sports Med. 2011;45(4):238-244. PMID:21081640.

26. Myer GD, Ford KR, Khoury J, Succop P, Hewett TE. Clinical correlates to laboratory measures for use in non-contact anterior cruciate ligament injury risk prediction algorithm. Clin Biomech (Bristol, Avon). 2010;25(7):693-699. PMID:20554101.

27. Myer GD, Ford KR, Khoury J, Succop P, Hewett TE. Development and validation of a clinic-based prediction tool to identify female athletes at high risk for anterior cruciate ligament injury. Am J Sports Med. 2010;38(10):2025-2033. PMID:20595554.

28. Myer GD, Martin L, Jr., Ford KR, et al. No association of time from surgery with functional deficits in athletes after anterior cruciate ligament reconstruction: evidence for objective return-to-sport criteria. Am J Sports Med. 2012;40(10):2256-2263. PMID:22879403.

29. Myer GD, Paterno MV, Ford KR, Quatman CE, Hewett TE. Rehabilitation after anterior cruciate ligament reconstruction: criteria-based progression through the return-to-sport phase. J Orthop Sports Phys Ther. 2006;36(6):385-402. PMID:16776488.

30. Narducci E, Waltz A, Gorski K, Leppla L, Donaldson M. The clinical utility of functional performance tests within one-year post-acl reconstruction: a systematic review. Int J Sports Phys Ther. 2011;6(4):333-342. PMID:22163095.

31. Neeter C, Gustavsson A, Thomee P, Augustsson J, Thomee R, Karlsson J. Development of a strength test battery for evaluating leg muscle power after anterior cruciate ligament injury and reconstruction. Knee Surg Sports Traumatol Arthrosc. 2006;14(6):571-580. PMID:16477472.

32. Nilstad A, Andersen TE, Bahr R, Holme I, Steffen K. Risk factors for lower extremity injuries in elite female soccer players. Am J Sports Med. 2014;42(4):940-948. PMID: 24500914.

33. Padua DA, Marshall SW, Boling MC, Thigpen CA, Garrett WE, Jr., Beutler AI. The Landing Error Scoring System (LESS) Is a valid and reliable clinical assessment tool of jump-landing biomechanics: The JUMP-ACL study. Am J Sports Med. 2009;37(10):1996-2002. PMID: 19726623.

34. Paterno MV, Rauh MJ, Schmitt LC, Ford KR, Hewett TE. Incidence of contralateral and ipsilateral anterior cruciate ligament (ACL) injury after primary ACL reconstruction and return to sport. Clin J Sport Med. 2012;22(2):116-121. PMID:22343967. 
35. Paterno MV, Rauh MJ, Schmitt LC, Ford KR, Hewett TE. Incidence of Second ACL Injuries 2 Years After Primary ACL Reconstruction and Return to Sport. Am J Sports Med. 2014;42(7):1567-1573. PMID: 24753238.

36. Paterno MV, Schmitt LC, Ford KR, et al. Biomechanical measures during landing and postural stability predict second anterior cruciate ligament injury after anterior cruciate ligament reconstruction and return to sport. Am J Sports Med. 2010;38(10):1968-1978. PMID:20702858.

37. Pinczewski LA, Lyman J, Salmon LJ, Russell VJ, Roe J, Linklater J. A 10-year comparison of anterior cruciate ligament reconstructions with hamstring tendon and patellar tendon autograft: a controlled, prospective trial. Am J Sports Med. 2007;35(4):564-574. PMID:17261567.

38. Plisky PJ, Rauh MJ, Kaminski TW, Underwood FB. Star Excursion Balance Test as a predictor of lower extremity injury in high school basketball players. J Orthop Sports Phys Ther. 2006;36(12):911-919. PMID:17193868.

39. Quatman CE, Hewett TE. The anterior cruciate ligament injury controversy: is "valgus collapse" a sex-specific mechanism? Br J Sports Med. 2009;43(5):328-335. PMID:19372087.

40. Stearns KM, Pollard CD. Abnormal frontal plane knee mechanics during sidestep cutting in female soccer athletes after anterior cruciate ligament reconstruction and return to sport. Am J Sports Med. 2013;41(4):918-923. PMID:23425687.

41. Thomée R, Kaplan Y, Kvist J, et al. Muscle strength and hop performance criteria prior to return to sports after ACL reconstruction. Knee Surg Sports Traumatol Arthrosc. 2011;19(11):1798-1805. PMID:21932078.

42. Waldén M, Hägglund M, Ekstrand J. High risk of new knee injury in elite footballers with previous anterior cruciate ligament injury. Br J Sports Med. 2006;40(2):158-162; discussion 158-162. PMID:16432004.

43. Waldén M, Hägglund M, Werner J, Ekstrand J. The epidemiology of anterior cruciate ligament injury in football (soccer): a review of the literature from a gender-related perspective. Knee Surg Sports Traumatol Arthrosc. 2011;19(1):3-10.

PMID:20532868. 
Supplementary Appendix. Functional performance tests

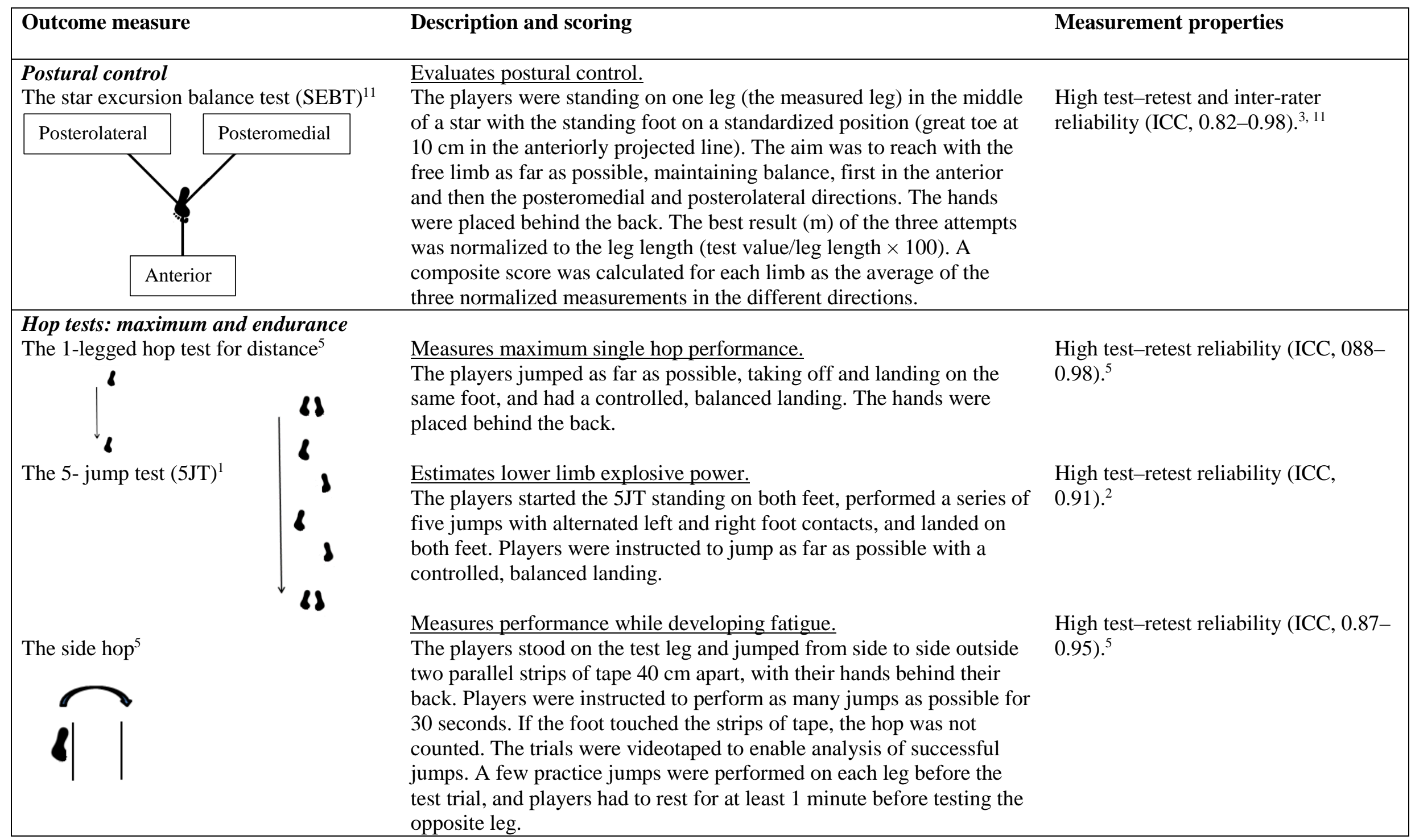




\section{Hop tests: Movement asymmetries}

The drop vertical jump (DVJ) $)^{7,9,10}$

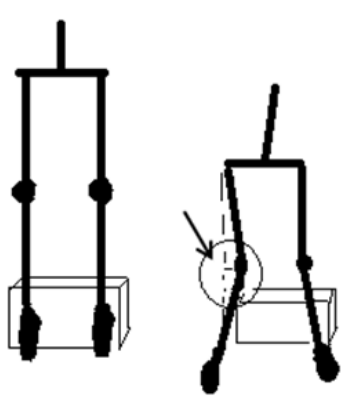

Measures knee motion in frontal plane and pKAM.

The players stood on a box (31 cm high) with their feet on marks 35 cm apart. Players were instructed to drop down and immediately jump as high as possible and try to reach, with both arms, a suspended ball at a height of $260 \mathrm{~cm}$. Data were captured with two video cameras

(Panasonic HC-V500M), $70 \mathrm{~cm}$ high, one on frontal plane, $3.5 \mathrm{~m}$ from player and one on sagittal plane, $2.5 \mathrm{~m}$ from expected landing position. Video was recorded at 50Hz with AVCHD Full HD at 1080/50p. To ensure that the cameras were aligned with the target motion plane, preset templates were used, where angles were checked and marked. The three jumps were assessed from the films. The assessment was based on the quality of the performed jump in the frontal plane including symmetry in the take-off and landing from the box, knee motion, feet position at landing, and weight displacement. The worst assessed jump of the three trials, summarized from all criteria, was used in the analysis. Knee motion (medial/valgus or lateral/varus knee

displacement) was calculated in $\mathrm{m}$ as the frontal plane displacement of the knee from initial contact to the end of the deceleration phase of the DVJ. The knee flexion ROM (degrees) was also measured from initial contact to the end of the deceleration phase of the DVJ. To simplify the measurement, the greater trochanter, the lateral knee joint line, the head of the fibula, lateral malleolus, patella tendon, and center of the patella were marked with a marker pen. Knee motion and flexion angle, measured with motion analysis software Dartfish ProSuite (Dartfish Ltd, Fribourg, Switzerland), were used to calculate knee abduction moment (KAM) according to a nomogram to predict the probability of high knee abduction moment (pKAM). ${ }^{7}$ The range of pKAM is $0-1$, which is comparable to 0 (lowest) $-100 \%$ (highest). The nomogram is based on the player's weight, tibia length, knee motion in the frontal plane, and knee flexion ROM, and a surrogate value for hamstring-quadriceps ratio (multiplying the player's mass by 0.01 and adding the resultant value to 1.10$)^{7,9,10}$
This clinic-based technique has shown high correlation with simultaneous laboratory-based measurements, ${ }^{7,10}$ with most variables having good to excellent reliability (ICC, 0.75-0.99). ${ }^{4}$

\section{Biomechanical laboratory} measurements predict high KAM landing mechanics with high sensitivity (85\%) and specificity (93\%). ${ }^{7}$ Clinical correlates to

laboratory-based measures and high KAM is predicted with high sensitivity (73-84\%) and specificity $(67-71 \%).)^{7,9,10}$ 
The tuck jump ${ }^{8}$

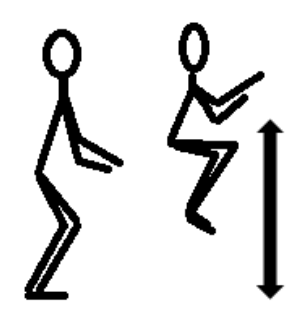

Identifies movement asymmetries in a plyometric activity. The players performed repeated tuck jumps for 10 seconds. The instructions were to lift the knees to hip height and attempt to land in the same place. Two standard video cameras, one in the frontal and one in the sagittal plane, $5 \mathrm{~m}$ and $3.5 \mathrm{~m}$ from the test person, respectively, were used. The tuck jump was analyzed from the films by the same person, who was blinded to group belonging, according to a clinicianfriendly screening tool. ${ }^{6}$ The screening tool consists of 10 criteria grouped into 3 areas: knee and thigh motion, foot position during landing, and plyometric technique. Six or more flawed techniques are considered as abnormal. Flawed techniques are e.g., thighs not equal side-to-side, lower extremity valgus at landing, foot placement not parallel, pause between jumps, techniques declining during the 10 seconds.
Inter- $(k=0.88)$ and intra-tester reliability $(k=0.86-1.0)$ are very good-excellent when the test is analyzed from video. ${ }^{6}$

\section{References}

1. Chamari K, Chaouachi A, Hambli M, Kaouech F, Wisloff U, Castagna C. The five-jump test for distance as a field test to assess lower limb explosive power in soccer players. J Strength Cond Res. 2008;22(3):944-950.

2. Chaouachi A, Brughelli M, Chamari K, et al. Lower limb maximal dynamic strength and agility determinants in elite basketball players. $J$ Strength Cond Res. 2009;23(5):1570-1577.

3. Clark RC, Saxion CE, Cameron KL, Gerber JP. Associations between three clinical assessment tools for postural stability. N Am J Sports Phys Ther. 2010;5(3):122130.

4. Ford KR, Myer GD, Hewett TE. Reliability of landing 3D motion analysis: implications for longitudinal analyses. Med Sci Sports Exerc. 2007;39(11):2021-2028.

5. Gustavsson A, Neeter C, Thomée P, et al. A test battery for evaluating hop performance in patients with an ACL injury and patients who have undergone ACL reconstruction. Knee Surg Sports Traumatol Arthrosc. 2006;14(8):778-788.

6. Herrington L, Myer GD, Munro A. Intra and inter-tester reliability of the tuck jump assessment. Phys Ther Sport. 2013;14(3):152-155.

7. Myer GD, Ford KR, Hewett TE. New method to identify athletes at high risk of ACL injury using clinic-based measurements and freeware computer analysis. Br $J$ Sports Med. 2011;45(4):238-244.

8. $\quad$ Myer GD, Ford KR, Hewett TE. Tuck Jump Assessment for Reducing Anterior Cruciate Ligament Injury Risk. Athl Ther Today. 2008;13(5):39-44.

9. Myer GD, Ford KR, Khoury J, Succop P, Hewett TE. Clinical correlates to laboratory measures for use in non-contact anterior cruciate ligament injury risk prediction algorithm. Clin Biomech (Bristol, Avon). 2010;25(7):693-699.

10. Myer GD, Ford KR, Khoury J, Succop P, Hewett TE. Development and validation of a clinic-based prediction tool to identify female athletes at high risk for anterior cruciate ligament injury. Am J Sports Med. 2010;38(10):2025-2033.

11. Plisky PJ, Rauh MJ, Kaminski TW, Underwood FB. Star Excursion Balance Test as a predictor of lower extremity injury in high school basketball players. J Orthop Sports Phys Ther. 2006;36(12):911-919. 